\title{
Extraction and on-Fiber Derivatization of Chlorophenols in Leather by Internally Cooled Solid Phase Microextraction
}

\author{
Cristine D. de Souza Silveira, ${ }^{a}$ Josias Merib, ${ }^{a}$ Edmar Martendal ${ }^{b}$ and Eduardo Carasek ${ }^{*, a, c}$ \\ ${ }^{a}$ Departamento de Química, Universidade Federal de Santa Catarina, 88040-900 Florianópolis-SC, Brazil \\ ${ }^{b}$ Departamento de Química, Universidade do Estado de Santa Catarina, 89219710 Joinville-SC, Brazil \\ 'Instituto Nacional de Ciência e Tecnologia de Bioanalítica, CP 6154, 13083-970 Campinas-SP, Brazil
}

\begin{abstract}
Neste estudo é proposto um novo procedimento analítico para a determinação de fenóis em amostras de couro utilizando a técnica de microextração em fase sólida refrigerada internamente (CF-SPME) com derivatização direta na fibra e cromatografia gasosa acoplada a espectrometria de massas com monitoramento de íons selecionados (GC-SIM-MS). As condições experimentais para a extração e derivatização foram otimizadas utilizando procedimentos quimiométricos, sendo tempo de extração e temperatura da amostra de 5 min e $170{ }^{\circ} \mathrm{C}$, temperatura do recobrimento da fibra de $20^{\circ} \mathrm{C}$, e exposição da fibra ao headspace de $70 \mu \mathrm{L}$ do agente derivatizante bis(trimetilsilil) trifluor-acetamida por 23 min. Limites de detecção variaram entre 1,03 e 2,68 $\mu \mathrm{g} \mathrm{g}^{-1}$ e o desvio padrão relativo $(\mathrm{RSD})$ foi menor que $15 \%(\mathrm{n}=5)$. Estudos de recuperações em três níveis de concentração variaram entre 64,5 e $92,3 \%$.
\end{abstract}

This study proposes a new analytical procedure based on an internally cooled solid phase microextraction technique (CF-SPME) combined with on-fiber derivatization and gas chromatography-selected ion monitoring-mass spectrometry (GC-SIM-MS) for the determination of phenols extracted directly from leather samples. The extraction and derivatization conditions were optimized using experimental designs, such as: extraction time and sample temperature of 5 min and $170{ }^{\circ} \mathrm{C}$, fiber recoat temperature of $20^{\circ} \mathrm{C}$, and exposing the fiber to the headspace of $70 \mu \mathrm{L}$ of bis(trimethylsylyl)trifluoro-acetamide derivatizing agent for $23 \mathrm{~min}$. Detection limits ranging from 1.03 to $2.68 \mu \mathrm{g} \mathrm{g}^{-1}$ and relative standard deviation (RSD) lower than $15 \%(\mathrm{n}=5)$ were obtained. The recovery was studied at three concentration levels and excellent recoveries ranging from 64.5 to $92.3 \%$ were obtained.

Keywords: cold fiber SPME, phenols, leather, gas chromatography-mass spectrometry, experimental designs

\section{Introduction}

Phenols and their derivatives have been widely used in the industrial sector for some time, but in recent decades their use has been restricted due to their high toxicity and the potential hazard they represent to human health. ${ }^{1}$ These compounds are frequently found in tap and surface waters, soils and effluents originating from the production of leather, paint, petroleum, pesticides, cellulosic pulp and paper, and even in some manufactured products. ${ }^{2}$

The development of sensitive analytical methods for the determination of contaminants in solid matrices originating from industrial processes represents a considerable

\footnotetext{
*e-mail: eduardo.carasek@ufsc.br
}

challenge due to the strong interaction between the analyte and the matrix. The analytical methods commonly proposed include supercritical fluid extraction, ${ }^{3}$ liquid extraction ${ }^{4}$ and solid phase extraction. ${ }^{5,6}$ However, the above-mentioned methods have disadvantages such as being of high cost and time-consuming, and they often require the use of large volumes of organic solvents. Considering that sample preparation is usually the most time-consuming step and generates a larger error in instrumental analysis, sample preparation methods characterized by simplicity, reproducibility, low use of organic solvents and effective in terms of sample clean-up have been developed. Sample preparation techniques such as solid phase microextraction, stir bar sorptive extraction, liquid phase microextraction, dispersive liquid-liquid microextraction 
and liquid-liquid-liquid microextraction have been employed to extract contaminants from solid matrices. ${ }^{6}$

A sample preparation method that has been successfully applied in the determination of volatile organic compounds in the headspace of complex matrices is internally cooled SPME. Cold fiber solid phase microextraction technique (CF)-SPME has been employed in the extraction of poly-cyclic aromatic hydrocarbons (PAHs) from soil and sediment samples, ${ }^{7}$ fragrances from Iranian rice samples ${ }^{8}$ and off-flavor compounds in cork stopper samples ${ }^{9}$ as well as to determine the aroma profile of tropical fruits. ${ }^{10}$ Physico-chemical studies to investigate the desorption kinetics of PAHs from solid samples ${ }^{11}$ and photodegradation products of hexachlorobenzene ${ }^{12}$ have also been carried out using CF-SPME. Basically, in the cold fiber method the fiber is maintained at low temperature in the headspace of the sample heated to high temperatures. Heating the sample to an elevated temperature increases the release of analytes from the matrix increasing their concentration in the headspace, while the use of lower fiber temperature overcomes the exothermic consequences of SPME and thus increases the analyte/fiber coating partition coefficient.

In this study, the use of a CF-SPME technique in headspace mode (CF-HS-SPME) followed by on-fiber derivatization for direct and exhaustive extraction of phenols from leather is reported. To assure the best extraction and derivatization conditions, the CF-HS-SPME system was optimized using experimental design procedures.

\section{Experimental}

\section{Chemicals and reagents}

Certified standards of phenols [phenol(P), 2-methylphenol (2MP), 4-methylphenol (4MP), 3-methylphenol (3MP), 2-chlorophenol (2CP), 3-chlorophenol (3CP), 4-chlorophenol (4CP) 2,4-dimethylphenol (2,4dMP)] were obtained at concentrations of $2000 \mathrm{mg} \mathrm{L}^{-1}$ in methanol (Supelco, Bellefonte, USA). Working solutions were prepared by diluting stock solutions with methanol (Sigma Aldrich, Steinheim, Germany). Bis(trimethylsylyl) trifluoro-acetamide (BSTFA) (Supelco, Bellefonte, USA) was used for the derivatization procedure.

"Wet blue" leather samples were supplied by the Instituto Brasileiro de Tecnologia do Couro e Artefatos (Novo Hamburgo, Rio Grande do Sul, Brazil).

\section{Instrumentation}

All of the chromatography analyses were carried out using a Shimadzu GC-MS QP 2010 Plus instrument.
The Rtx-5MS column $(30 \mathrm{~m} \times 0.25 \mathrm{~mm} \times 0.25 \mu \mathrm{m})$ manufactured by Restek (Bellefonte, PA, USA) was used for the GC separation. Helium (99.999\%) was used as the

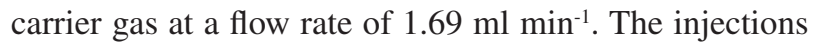
were performed in the splitless mode during the first minute of the chromatographic run, followed by a split ratio of $1: 100$. The initial oven temperature was $50^{\circ} \mathrm{C}$ which was increased at $5{ }^{\circ} \mathrm{C} \mathrm{min}^{-1}$ to $200^{\circ} \mathrm{C}$. The injector temperature was $290{ }^{\circ} \mathrm{C}$ and the fiber desorption time was $10 \mathrm{~min}$. Desorption conditions were fixed so that no memory effects were observed. The transfer line and the ion source temperatures were set at 200 and $210^{\circ} \mathrm{C}$, respectively. The ionization was carried out in SIM mode to increase the detection selectivity and sensitivity. The ions selected for the quantification and identification of the target analytes in their derivative form (m/z ratio) were: 91-165-180 (2MP, 4MP, 3MP), 185-200-187 (3CF, 4CP), 93-149-185 (2CP), 151-152-166 (P), 105-179-195 (2,4dMP).

The cold fiber device, temperature controller and solenoid valve used in this study have been described in previous papers..$^{7-12}$ A poly-dimethyl siloxane (PDMS) hollow membrane with $178 \mu \mathrm{m}$ wall thickness and $1 \mathrm{~cm}$ length was used as the extraction phase. Liquid $\mathrm{CO}_{2}$ was used to cool the fiber coating.

The sample temperature was controlled using a heater device especially built to carry out the CF-SPME studies (Dist, Florianópolis, Brazil). All manipulations of the cold fiber device as well as the changing of the fiber temperatures were carried out manually.

\section{Leather sample preparation}

All of the extractions were carried out in the headspace mode. Leather samples $(100 \mathrm{mg}$ ) free of the target analytes were cut into cubes of approximately $2 \mathrm{~mm}^{2}$ and added to $15 \mathrm{~mL}$ vials. The samples were spiked with $4 \mu \mathrm{L}$ of the phenol standard solution ( $\left.400 \mathrm{mg} \mathrm{L}^{-1}\right)$ and left for at least $24 \mathrm{~h}$ at $4^{\circ} \mathrm{C}$ to allow strong interactions between the sample matrix and analytes to occur.

\section{CF-HS-SPME procedure}

The vial containing the sample was introduced into the heater device at the appropriate temperature (selected according to the experimental optimization design procedure). Subsequently, the CF-HS-SPME device was manually inserted into the sealed vial through the septum and the fiber was exposed to the sample headspace for the specified extraction time. Following the sampling procedure, the CF-HS-SPME fiber was inserted into the headspace of a sealed $4 \mathrm{~mL}$ vial containing the BSTFA agent under constant agitation. The exposure time and 
BSTFA volume was defined according to the experimental design procedure. After these two steps, the fiber was immediately inserted into the GC-MS injector and the analytes were thermally desorbed from the fiber for $10 \mathrm{~min}$ at $290^{\circ} \mathrm{C}$.

\section{Optimization strategy}

The optimization of the extraction procedure was carried out in two steps. In the first step the variables sample temperature $\left(80-170{ }^{\circ} \mathrm{C}\right)$, extraction time $(5-25 \mathrm{~min})$ and fiber temperature $\left(5-30{ }^{\circ} \mathrm{C}\right)$ were evaluated by a two-level full factorial design. In a second step the fiber temperature $\left(10-50{ }^{\circ} \mathrm{C}\right)$ was optimized by a univariate procedure. For both steps the procedure was carried out using BSTFA at $50 \mu \mathrm{L}$ and $15 \mathrm{~min}$ of fiber exposure to the headspace of the derivative agent. The variables derivative agent volume (25-100 $\mu \mathrm{L})$ and time of exposure to the headspace of the BSTFA (5-30 min) were optimized through a Doehlert design. The geometric mean for the peak area of phenols was used as the experimental data for processing using the Statistica ${ }^{\circledR} 6.0$ computer program. All experiments were carried out in duplicate except for the center point (triplicate).

Evaluation of quantitative extraction of phenols from leather using CF-HS-SPME

In order to evaluate whether the extraction using the CF-HS-SPME technique is exhaustive, a study was carried out by applying the optimized procedure to the same sample twice. The absolute recoveries were calculated using the equation $\mathrm{R}=\left(1-\mathrm{n}_{2}\right) / \mathrm{n}_{1}$, where $\mathrm{n}_{1}$ and $\mathrm{n}_{2}$ are the peak areas corresponding to the first and second extraction, respectively. After the first extraction procedure the fiber was removed from the sample vial and inserted into the derivatizing agent vial. After the thermal desorption of the analytes in the GC injector port, the cold fiber system was inserted again into the same sample vial which had been kept in the ice bath, and this vial was then reintroduced into the heater block. When the sample temperature stabilized at the selected value, the fiber was exposed to the sample headspace and the procedure described above was repeated.

\section{Results and Discussion}

The procedure used in this study to optimize the proposed method consisted of two steps. The first, focused on obtaining the best experimental conditions to extract phenols from leather using the CF-HS-SPME procedure. The second step focused on the derivatization procedure using the derivatizing agent BSTFA. In both cases experimental designs were used. Finally, the analytical performance parameters for all target compounds using the method developed were determined.

\section{Optimization of CF-HS-SPME procedure}

A two-level $2^{3}$ full factorial design with a central point was applied to determine the influence of selected factors (extraction time, sample temperature and fiber temperature) and their interactions in the CF-HS-SPME system. Figure 1 shows the main effects and their interactions, according to the full factorial design, with the sample and fiber temperatures being highly significant as well as the interaction between them. On the other hand, by considering the set conditions within the experimental domain the extraction time was not significant and thus it was fixed at $5 \mathrm{~min}$ for all experiments. However, according to the factorial study, on increasing the sample and fiber temperatures the recovery efficiency improves. As the sample temperature at the high level $\left(170{ }^{\circ} \mathrm{C}\right)$ of the experimental design was already very high value, and to minimize leaking of the analytes, this variable was fixed at $170{ }^{\circ} \mathrm{C}$. Since the interaction between the sample and fiber temperatures was significant and the curve indicates that the response is not linear in the range evaluated, a final optimization of the fiber temperature was carried out with a univariate procedure. The results obtained in this study indicated that the optimum fiber temperature is $20^{\circ} \mathrm{C}$, as shown in Figure 2.

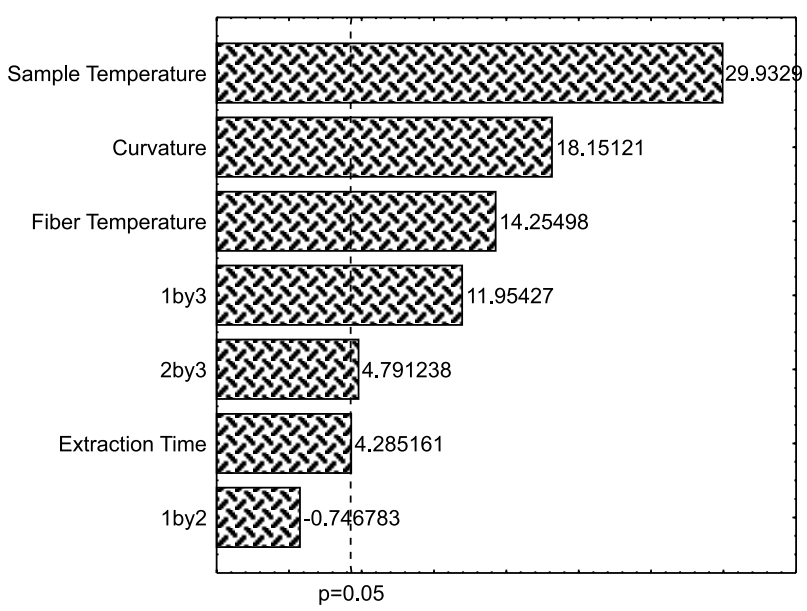

Figure 1. Results obtained for the full factorial $2^{3}$ design carried out for the optimization of the variables (1) fiber temperature, (2) extraction time and (3) sample temperature.

\section{Optimization of derivatization procedure}

The relationship between the time of exposure of the fiber to the derivatizing agent vapor and the volume of BSTFA was observed using the Doehlert matrix and the 


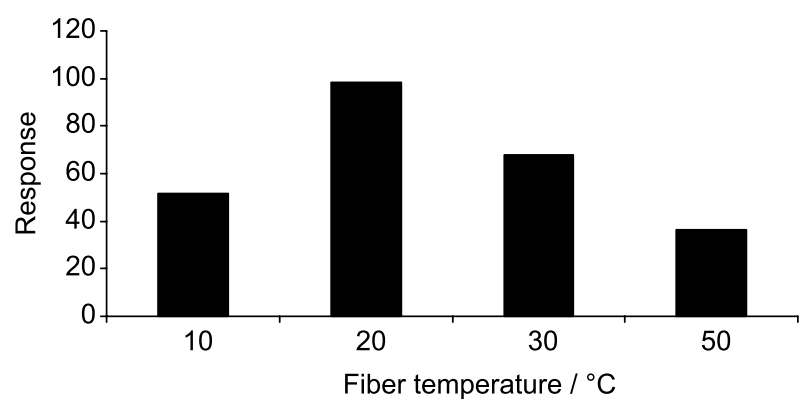

Figure 2. Results obtained for the optimization of fiber temperature.

surface response is presented in Figure 3. The volume of the vial was fixed at $4 \mathrm{~mL}$. The findings of this study suggest a relationship between the variables investigated. By analyzing the response surface, the optimum derivatization conditions that generate the best signal for all target analytes corresponded to an exposure time of $23 \mathrm{~min}$ and $70 \mu \mathrm{L}$ of BSTFA.

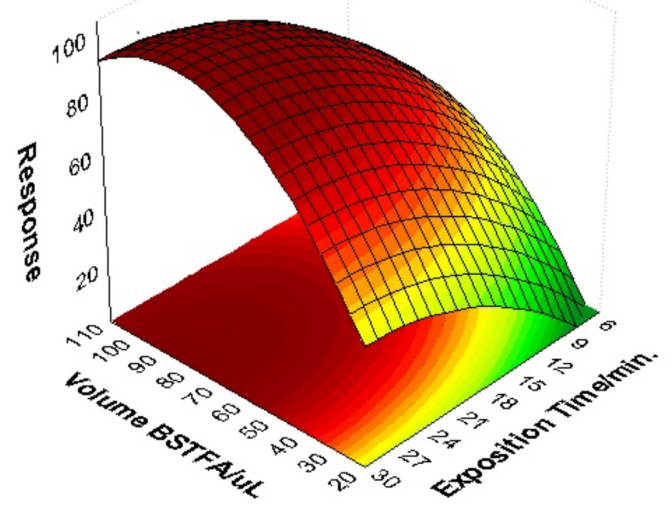

Figure 3. Response surface obtained using Doehlert design for the optimization of the BSTFA volume and time of exposure of the fiber to the derivatizing agent BSTFA.

\section{Quantitative extraction of phenols from leather}

New information on exhaustive extraction using the CF-SPME procedure was explored in this study. In this regard the amount of analyte present in a second extraction of the same sample (100 mg of leather at $20 \mu \mathrm{g} \mathrm{g}^{-1}$ ) was determined. The results of the successive extractions, shown in Table 1, illustrate that the exhaustive extraction (75-85\%) of phenols from leather occurred using the optimized conditions in the first extraction. This is a very interesting feature of the method, as it facilitates the calibration procedure and improves its accuracy.

\section{Analytical performance parameters}

A calibration curve was constructed for the phenols investigated in this study under the optimum CF-HS-SPME and derivatization conditions. A blank leather sample was
Table 1. Successive extractions of phenols from the leather

\begin{tabular}{lcc}
\hline Analyte & $\begin{array}{c}\text { Recovery of first } \\
\text { extraction / } \%\end{array}$ & $\begin{array}{c}\text { Recovery of second } \\
\text { extraction / \% }\end{array}$ \\
\hline $\mathrm{P}$ & 83 & 14 \\
$2 \mathrm{MP}$ & 80 & 16 \\
$3 \mathrm{MP}$ & 75 & 19 \\
$4 \mathrm{MP}$ & 77 & 18 \\
$2 \mathrm{CP}$ & 79 & 17 \\
$4 \mathrm{CP}$ & 85 & 13 \\
$2,4 \mathrm{dMP}$ & 82 & 15 \\
$3 \mathrm{CP}$ & 83 & 14 \\
\hline
\end{tabular}

used for this purpose. Table 2 summarizes the results obtained for some parameters of merit when using the procedure described in section 2.4. The limits of detection and quantification were calculated as three and ten times the signal to noise ratio, respectively. Good correlation coefficients were obtained in the studied linear range (3.42 and $80 \mu \mathrm{g} \mathrm{g}^{-1}$ ) with $\mathrm{R}$ values of at least 0.9947 . Detection limits were satisfactory, being close to those obtained in other studies reported in the literature for the determination of phenols in solid matrices such as leather and wood. The precision of the proposed method was verified through five leather samples spiked with phenols at $20 \mu \mathrm{g} \mathrm{g}^{-1}$ with results ranging between 8.28 and $15.48 \%$ (Table 2).

Table 2. Analytical figures of merit obtained for the optimized CF-HS-SPME method

\begin{tabular}{lcccc}
\hline Analytes & $\begin{array}{c}\text { Linear range / } \\
\left(\mu \mathrm{g} \mathrm{g}^{-1}\right)\end{array}$ & $\mathrm{R}^{\mathrm{a}}$ & $\begin{array}{c}\mathrm{LOD}^{\mathrm{b} /} \\
\left(\mu \mathrm{g} \mathrm{g}^{-1}\right)\end{array}$ & $\begin{array}{c}\mathrm{RSD}^{\mathrm{c} /} \\
\%\end{array}$ \\
\hline $\mathrm{P}$ & $7.4-80.0$ & 0.9989 & 2.23 & 12 \\
$2 \mathrm{MP}$ & $3.8-80.0$ & 0.9958 & 1.15 & 15 \\
$3 \mathrm{MP}$ & $4.2-80.0$ & 0.9966 & 1.27 & 13 \\
$4 \mathrm{MP}$ & $3.8-80.0$ & 0.9957 & 1.13 & 9 \\
$2 \mathrm{CP}$ & $3.4-80.0$ & 0.9947 & 1.03 & 12 \\
$4 \mathrm{CP}$ & $5.3-80.0$ & 0.9978 & 1.58 & 8 \\
$2,4 \mathrm{dMP}$ & $8.9-80.0$ & 0.9992 & 2.68 & 11 \\
3CP & $6.4-80.0$ & 0.9978 & 1.92 & 11 \\
\hline
\end{tabular}

${ }^{a} \mathrm{R}$ : correlation coefficient; ${ }^{\mathrm{b}} \mathrm{LOD}$ : limit of detection; ${ }^{\mathrm{C}} \mathrm{RSD}$ : relative standard deviation $(\mathrm{n}=5)$.

Three leather samples were submitted to the newly developed CF-HS-SPME method, and the target compounds were not detected in significant amounts, probably because the use of these compounds in leather treatment has been restricted in Brazil since 2006. ${ }^{13}$ Thus, the samples were spiked with the target phenols at three concentration levels (20, 40 and $80 \mu \mathrm{g} \mathrm{g}^{-1}$ ) and the recovery was compared 
with the calibration curve obtained using a blank leather sample. Excellent recoveries (in the range of 64.6-92.3\%) were obtained, indicating that the method is reliable for the determination of these compounds in leather samples (Table 3).

Table 3. Study on recovery of phenols using three levels of phenol concentration in leather samples

\begin{tabular}{|c|c|c|c|}
\hline \multirow{2}{*}{ Analytes } & Level $1(20)^{\mathrm{a}}$ & Level $2(40)^{\mathrm{a}}$ & Level $3(80)^{\mathrm{a}}$ \\
\hline & \multicolumn{3}{|c|}{ Recovery / \% } \\
\hline $\mathrm{P}$ & 81.5 & 92.3 & 91.1 \\
\hline $2 \mathrm{MP}$ & 77.7 & 83.8 & 79.9 \\
\hline $3 \mathrm{MP}$ & 88.5 & 85.0 & 86.0 \\
\hline $4 \mathrm{MP}$ & 78.6 & 78.8 & 83.8 \\
\hline $2 \mathrm{CP}$ & 73.3 & 67.5 & 64.6 \\
\hline $4 \mathrm{CP}$ & 72.7 & 82.5 & 78.2 \\
\hline 2,4dMP & 74.5 & 88.5 & 85.7 \\
\hline $3 \mathrm{CP}$ & 81.4 & 83.5 & 81.0 \\
\hline
\end{tabular}

anit: $\mu g g^{-1}$.

Despite the target analytes were not detected in leather samples analyzed in this study, the developed method is valuable because of this analysis is a requisite for exporting of leather-based products (such as shoes and handbags) in order to assure that these products are phenols-free. Therefore, the analysis of the matrix/analytes proposed in this study is essential for exporting requirements, such as for the European Community. Furthermore, the prohibition of use is not a guarantee that these compounds have not been used underhand. The development of this method came from a real necessity, since a conventional method to determine phenols in leather is based on Soxhlet, which requires a large volume of solvents and time for analysis.

\section{Conclusions}

The method using CF-HS-SPME and on-fiber derivatization was shown to be sensitive, precise and accurate. Furthermore, this is a simple and very fast method requiring only small amounts of sample and no pre-treatment of complex samples prior to the extraction procedure.

\section{Acknowledgements}

The authors are grateful to CNPq for the financial resources which made this research possible. CNPq is also acknowledged for providing a doctoral fellowship to C. D. S. S. and a research fellowship to E. C.

\section{References}

1. Buchholz, K. D.; Pawliszyn, J.; Anal. Chem. 1994, 66,160.

2. Favaro, G.; De Leo, D.; Tastore, P.; Magno, F.; Ballardin, A.; J. Chromatogr. A 2008, 1177, 36.

3. Chen, J-L.; Liu, C-Y.; Anal. Chim. Acta 2005, 528, 83.

4. Ganeshjeevan, R.; Chandrasekar, R.; Kadigachalam, P.; Radhakrishnan, G.; J. Chromatogr., A 2007, 1140, 168.

5. Martínez-Uruñuela, A.; Rodríguez, I.; Cela, R.; Gonzáles-Sáiz, J. A.; Pizarro, C.; Anal. Chim. Acta 2005, 549, 117.

6. Morais, P.; Stoichev, T.; Clara, M.; Basto, P.; Vasconcelos, M. T. S. D.; Talanta 2012, 89, 1.

7. Ghiasvand, A. R.; Hosseinzadeh, S.; Pawliszyn, J.; J. Chromatogr., A 2006, 1124, 35.

8. Ghiasvand, A. R.; Setkova, L.; Pawliszyn, J.; Flavour Fragr. J. 2007, 22, 377.

9. Carasek, E.; Cudjoe, E.; Pawliszyn, J.; J. Chromatogr., A 2007, 1138,10 .

10. Carasek, E.; Pawliszyn, J.; J. Agric. Food Chem. 2006, 54, 8688.

11. Haddadi, S. H.; Niri, V. H.; Pawliszyn, J.; Anal. Chim. Acta 2009, 652, 224.

12. Sanchez-Prado, L.; Risticevic, S.; Pawliszyn, J.; Psillakis, E.; J. Photochem. Photobiol. 2009, 206, 227.

13. Resolution RDC No. 164 from the National Health Surveillance Agency (ANVISA), Prohibition and the Use of the Active Ingredient Pentachlorophenol and its Salts, August, 2006, Brasília, DF, Brasil.

Submitted: July 12, 2012

Published online: January 16, 2013

FAPESP has sponsored the publication of this article. 